\title{
Clinical adverse events profile during combination therapy with amlodipine and hydrochlorothiazide in hypertensive Nigerians
}

\author{
G. B. S. Iyalomhe ${ }^{1, *}$, E. K. I. Omogbai ${ }^{2}$, A. O. Isah ${ }^{3}$, S. I. Iyalomhe \\ ${ }^{1}$ Department of Pharmacology and Therapeutics, College of Medicine, Ambrose Alli University, Ekpoma, Nigeria \\ ${ }^{2}$ Department of Pharmacology and Toxicology, Faculty of Pharmacy, University of Benin, Benin City, Nigeria \\ ${ }^{3}$ Department of Internal Medicine, College of Medical Sciences, University of Benin, Benin City, Nigeria \\ ${ }^{4}$ Department of Public Health and Primary Health Care, Central Hospital, Auchi, Nigeria
}

\section{Email address:}

goddyiyalo@yahoo.com (G. B. S. Iyalomhe)

\section{To cite this article:}

G. B. S. Iyalomhe, E. K. I. Omogbai, A. O. Isah, S. I. Iyalomhe. Clinical Adverse Events Profile during Combination Therapy with Amlodipine and Hydrochlorothiazide in Hypertensive Nigerians. American Journal of Clinical and Experimental Medicine. Vol. 2, No. 6, 2014, pp. 165-170. doi: 10.11648/j.ajcem.20140206.19

\begin{abstract}
Background: Combination therapy with antihypertensive drugs from different classes has been recommended as an effective strategy to attain blood pressure (BP) goal. Although amlodipine (AML) and hydrochlorothiazide (HCZ) are frequently used as combination therapy in Nigeria, information regarding the adverse events associated with this regimen is scarce. Objective: To evaluate the clinical adverse events profile associated with a regimen of AML and HCZ therapy for 48 weeks (wks) in hypertensive Nigerians. Methods: Ninety male (M) and female (F) Nigerians aged 31-86 years with newly diagnosed uncomplicated essential hypertension (BP > 160/90 $\leq 180 / 120 \mathrm{mmHg}$ ), were enrolled. Patients, who were 30 each (15 Ms and $15 \mathrm{Fs}$ ) in AML, HCZ and AML-HCZ groups, were treated, respectively, with AML 5mg for 6 wks and the dose increased to $10 \mathrm{mg}$ till wk 12 (end of monotherapy) after which HCZ 25mg was added; HCZ $25 \mathrm{mg}$ till wk 6 (end of monotherapy) after which AML 5-10mg was added as needed; and AML 5-10mg + HCZ 25mg. Body mass index (BMI), BP and heart rate (HR) were assessed at baseline and at the end of wks 1, 3, 6, 12, 24, 36, and 48 during treatment. Adverse drug events were similarly monitored beginning from wk 1 . Results: The three combination regimens comparably significantly reduced $\mathrm{BP}$, though the effect in AML group was greater than the rest $(\mathrm{P}<0.05)$. Changes in BMI and HR were not statistically significant. Sixty one events of which polyuria, tachycardia and slight weight reduction were commonest as well as nausea and diaphoresis were recorded in AML group. Similarly, 91 events were observed in HCZ group, polyuria, tachycardia and weight loss being commonest plus impotence and visual disturbance. Although tachycardia and weight loss were more prominent among the 74 events in AML-HCZ group, polyuria was surprisingly uncommon. It is demonstrated that a regimen of AML to which HCZ is subsequently added provides superior tolerability and less bother to patients when compared with a regimen of HCZ to which AML is added as needed or with ab initio AML-HCZ combination therapy.
\end{abstract}

Keywords: Adverse Drug Events, Antihypertensive Combination Therapy, Amlodipine, Hydrochlorothiazide, Nigerians

\section{Introduction}

Hypertension, a leading cause of cardiovascular disease (CVD), has become the single most important cause of morbidity and mortality globally (1-3). The prevalence of hypertension has increased tremendously over the past two to three decades in Africa including Nigeria where hypertension and increasing urbanization have been close companions. This has not only become a significant public health and clinical problem but it is also having a huge negative economic impact because a sizeable proportion of the productive populace becomes chronically ill or die prematurely leaving their families in abject poverty and suffering (4-5).

Combination therapy using lower doses of different classes of antihypertensive drugs has been recommended to facilitate early attainment of goal BP, in stage 2 hypertension and also in patients with comorbid risk factors such as diabetes, heart failure and chronic kidney disease or when $\mathrm{BP} \geq 20 / 10$ $\mathrm{mmHg}$ above goal (6-7). Clinical evidence showed superior 
efficacy of such dual or multiple combinations over monotherapies, with reduced morbidity and mortality particularly with respect to stroke and coronary heart disease as well as modest adverse events being reported (8-10).

Adverse events from antihypertensive drugs are common. For example, in separate studies Kjellgren et al (11) and Morgan (12) found out that $42 \%$ and $33 \%$ of their samples of hypertensive patients, respectively, had their tablets changed because of adverse effects. In addition, side effects have been majorly responsible for self-reported antihypertensive nonadherence (13). Thus, many hypertensive patients lament that specific drugs are worse than the hypertension itself. They are unable to reconcile unwelcome adverse effects with reasons for taking the drugs because they feel quite well as asymptomatic hypertensives but start getting annoying side effects such as nausea or vomiting, diarrhea, constipation, orthostatic hypotension, dizziness or sleeping problems, tiredness, headache, palpitations, flushing, edema, frequent urination, nightmares and impotence, when taking the antihypertensive medications (14).

AML and HCV are widely used for the treatment of hypertension and their efficacy as well as tolerability has been well documented (8-10). However, information is scarce regarding the adverse events associated with dual combination therapy of AML and $\mathrm{HCZ}$ in hypertensive Nigerians. Resultantly, and based on our previous observations (9-10, 15-16), this randomized, open-label, prospective, two-centre study was undertaken to determine the adverse events profile associated with dual combination treatment with AML and HCV in hypertensive patients born and living in Nigeria.

\section{Patients and Methods}

\subsection{Study Subjects}

Ninety Nigerians of both gender with newly diagnosed essential hypertension ( stages 1\&2) attending Central Hospital and Osigbemhe Hospital both in Auchi, Edo State of Nigeria between March 2008 and March 2009 and aged 31 to 86 years, were recruited into the study. The sample size was estimated based on the number of Nigerians that are believed to be hypertensive (5).

\subsection{Inclusion and Exclusion Criteria}

Eligible participants had qualifying hypertension of BP > $160 / 90$ and $\leq 180 / 120 \mathrm{~mm} \mathrm{Hg}$ measured on at least 2 occasions in lying/supine, sitting and standing positions using standardized methods; had no identifiable cause of the hypertension; had no clinical evidence of cerebrovascular, cardiac, renal, hepatic, gastrointestinal or endocrinologic disease; had no hypersensitivity to AML and HCZ or related drugs; had no history of smoking, alcohol (drug) abuse or mental illness; had no need of any concomitant medication eg digitalis, non-steroidal anti-inflammatory drugs, psychotropic drugs, monoamine oxidase inhibitors, oral contraceptives, that may interact with the trial drugs. All Fs were non-lactating and non-pregnant.

\subsection{Controls}

These comprised the parallel age and sex-matched hypertensives on HCZ. For ethical reasons in the clinic setting, placebos were not used.

\subsection{Consent}

After suitable explanation, all literate patients gave informed written consent and the illiterates thumb-printed the consent form before the beginning of the study.

\subsection{Ethics Committees Approval}

The research protocol was reviewed and approved by the Ethics Committees of Irrua Specialist Teaching Hospital Irrua, Nigeria (Ambrose Alli University College of Medicine Teaching Hospital) and Central Hospital Auchi, Nigeria.

\subsection{Study Design}

Subjects were examined by a standardized pre-tested questionnaire seeking information on demographic data, the history of hypertension, current drugs if any, educational and social status, dietary habits, smoking and alcohol intake. The 90 patients were randomized to three groups (AML, HCZ, and AML-HCZ), each comprising of 30 patients divided into subgroups of $15 \mathrm{Ms}+15 \mathrm{Fs}$ using computer programgenerated random numbers.

\subsubsection{Measurements of Height, Weight (wt), Heart Rate $($ HR), Blood Pressure (BP) and 24 h Urine Volume}

A stadiometer scale (Seca model, UK) was used for measuring height $(\mathrm{m})$, with no shoes on; and a beam balance (Hackman, UK) was used to measure wt $(\mathrm{kg})$ while on light cloth. Body mass index (BMI) was computed as wt divided by height squared. Systolic BP (SBP) and diastolic BP (DBP), were measured with a standard mercury sphygmomanometer using the appropriate sized cuff (Riester Diplomat Presameter, Germany) with the subjects allowed to rest for 10 minutes before the determination using the left arm (with the cuff arm on the same level as the heart) at the sitting, standing and supine positions; always between $8 \mathrm{am}$ and $10 \mathrm{am}$, using standardized methods (17). Radial pulse was taken at both hands at the beginning and then at the right hand at every visit. HR was taken using the stethoscope diaphragm at the apex beat at every visit.

\subsection{Antihypertensive Intervention}

The patients in the AML group were treated initially with AML 5mg, and the dose was doubled after 6 weeks (wks) if BP was not controlled. Then after 12 weeks (end of monotherapy), HCZ $25 \mathrm{mg}$ was added if the desired BP was not achieved. In HCZ group, the patients were treated initially with HCZ 25mg for 6 weeks (end of monotherapy), after which AML 5mg was added if the BP was controlled. The dose of AML was doubled after 12 weeks if the BP was still not normalised. In the AML-HCZ group, the treatment 
was initiated with AML 5mg + HCZ 25mg. if the BP was not controlled after 6 weeks, the dose of AML was doubled. The outpatient treatment lasted 48 weeks. The patients were monitored closely with measurements taken before treatment and at the end of weeks 1, 3, 6,12,24,36, and 48 of treatment. Unequivocal patient identification was possible via a patient identification list consisting of the patient number, first name, and surname,

\subsubsection{Study Medications}

The medications AML and HCZ are licensed for long-term treatment of hypertension so that dangerous side effects due to the medicaments were not to be expected. AML 5mg and 10mg tablets (branded Amlovar ${ }^{\mathrm{R}}$ ), were donated by Neimeth International Pharmaceuticals Ikeja, Nigeria: NAFDAC Reg No A4-0333; Manufacturing Date 07-2007 and Expiry Date 07-2010. HCZ 25mg tablets (branded Esidrex $^{\mathrm{R}}$ ) were donated by Novartis Pharma SAS, France; NAFDAC Reg No OL-3705, Manufacturing Date 08-2007 and Expiry Date 08-2010.

\subsubsection{Course of Study and Methods for Recording Efficacy and Adverse Events}

All patients were encouraged to maintain their usual diet and regular physical activity but to avoid undue stress throughout the duration of the study. All patients were encouraged to take their drugs every morning. Each patient was observed for about 2 hours after taking medication drug for the first time. Adherence (compliance) in respect of intake of medication was encouraged by interviewing patients through phone calls, sporadic visits, pill counts

outside the view of patients. To preclude whitecoat effect, observer bias and to accurately assess the efficacy of the drugs, patients were followed up repeatedly at weeks 1, $3,6,12,24,36$, and 48. At each visit, volunteered or spontaneous report of adverse events were assessed for severity and association with treatment; and the attending physicians/investigators also recorded any adverse events they observed themselves or elicited from the patient through careful interrogation like "How do you feel?" No patient withdrew from the study because of adverse events.

Response to therapy was defined as a decrease in the mean trough sitting SBP and DBP of $10 \mathrm{~mm} \mathrm{Hg}$ or a drop to $<90$ $\mathrm{mm} \mathrm{Hg}$ with reduction of $>5 \mathrm{~mm} \mathrm{Hg}$. BP was regarded as normalised if the DBP was $<90 \mathrm{~mm} \mathrm{Hg}$ and SBP $<140 \mathrm{~mm}$ $\mathrm{Hg}$ BP. The effects of treatment on the various variables (except height) were assessed by comparing the values at each visit with the pretreatment baseline values.

\subsection{Data Analysis}

All data are presented as mean \pm SEM or mean \pm SD (for age, height and weight) using the general linear model procedure (PROC GLM) of the statistical analysis system (SAS) (2004). Where significant differences were noticed, mean separation was carried out using Duncan Multiple Range Test of the same SAS (2004) software. Correlation between two sets of variables was determined using Spearman's rank correlation. $\mathrm{P}<0.05$ was regarded as significant in all cases.

\section{Results}

Table 1. Demographic characteristics and baseline blood pressures of subjects in the AML, HCZ and AML-HCZ treatment groups

\begin{tabular}{|c|c|c|c|c|c|}
\hline \multirow{2}{*}{ Group } & \multirow{2}{*}{ Characteristics } & \multicolumn{2}{|l|}{ Male } & \multicolumn{2}{|l|}{ Female } \\
\hline & & Range & Mean \pm SD/SEM* & Range & Mean \pm SD/SEM \\
\hline \multirow{7}{*}{ AML } & Age (yrs) & $31-80$ & $60.80 \pm 14.03$ & $37-80$ & $63.60 \pm 8.02$ \\
\hline & Height (m) & $1.59-1.74$ & $1.66 \pm 0.04$ & $1.56-1.76$ & $1.66 \pm 0.07$ \\
\hline & Weight (kg) & $62-88$ & $76.77 \pm 8.94$ & $62-90.4$ & $79.80 \pm 8.85$ \\
\hline & BMI $\left(\mathrm{kg} / \mathrm{m}^{2}\right)$ & $24.84-29.75$ & $26.50 \pm 0.80$ & $25.48-30.13$ & $27.50 \pm 0.31$ \\
\hline & $\mathrm{WC}(\mathrm{cm})$ & 83-112 & $98.20 \pm 2.23$ & $88-117$ & $106.00 \pm 2.07^{*}$ \\
\hline & $\mathrm{SBP}(\mathrm{mm} \mathrm{Hg})$ & $150-175$ & $162.50 \pm 2.82$ & $150-180$ & $165.67 \pm 3.00^{*}$ \\
\hline & $\mathrm{DBP}(\mathrm{mm} \mathrm{Hg})$ & $100-115$ & $103.00 \pm 1.75$ & $90-115$ & $105.33 \pm 2.04^{*}$ \\
\hline \multirow{7}{*}{$\mathrm{HCZ}$} & Age (yrs) & $45-86$ & $63.80 \pm 12.02$ & $48-80$ & $65.47 \pm 10.15$ \\
\hline & Height (m) & $1.61-1.80$ & $1.69 \pm 0.05$ & $1.12-1.76$ & $1.67 \pm 0.04$ \\
\hline & Weight (kg) & $68-89$ & $75.37 \pm 6.27$ & $60-80$ & $73.44 \pm 6.30$ \\
\hline & $\operatorname{BMI}\left(\mathrm{kg} / \mathrm{m}^{2}\right)$ & $26.25-27.47$ & $26.50 \pm 0.32$ & $23.17-26.67$ & $24.50 \pm 0.42$ \\
\hline & $\mathrm{WC}(\mathrm{cm})$ & 88-108 & $97.73 \pm 1.50^{*}$ & $86-108$ & $96.73 \pm 1.48^{*}$ \\
\hline & $\mathrm{SBP}(\mathrm{mm} \mathrm{Hg})$ & $160-180$ & $170.33 \pm 2.09^{*}$ & $160-180$ & $169.00 \pm 1.90^{*}$ \\
\hline & DBP (mm Hg) & $95-115$ & $104.67 \pm 1.50^{*}$ & $90-115$ & $104.67 \pm 1.98^{*}$ \\
\hline \multirow{7}{*}{$\mathrm{AML}-\mathrm{HCZ}$} & Age (yrs) & $42-78$ & $62.13 \pm 11.89$ & $48-87$ & $69.93 \pm 11.60$ \\
\hline & Height (m) & $1.58-1.72$ & $1.64 \pm 0.04$ & $1.59-1.82$ & $1.67 \pm 0.06$ \\
\hline & Weight (kg) & $65-87.5$ & $74.33 \pm 7.07$ & $65-90.2$ & $77.21 \pm 8.67$ \\
\hline & BMI $\left(\mathrm{kg} / \mathrm{m}^{2}\right)$ & $26.10-29.66$ & $27.50 \pm 0.38$ & $25.79-27.33$ & $26.00 \pm 0.56$ \\
\hline & $\mathrm{WC}(\mathrm{cm})$ & $87-114$ & $100.50 \pm 2.01^{*}$ & $89-110$ & $99.5 \pm 2.06^{*}$ \\
\hline & $\mathrm{SBP}(\mathrm{mm} \mathrm{Hg})$ & $150-180$ & $165.00 \pm 4.57^{*}$ & $155-180$ & $167.50 \pm 4.44^{*}$ \\
\hline & DBP(mm Hg) & $100-115$ & $106.00 \pm 1.48^{*}$ & $90-120$ & $107.33 \pm 2.01^{*}$ \\
\hline
\end{tabular}

Characteristics and BPs in the groups are not significantly different; AML, Amlodipine; HCZ, Hydrochlorothiazide, AML-HCZ, AmlodipineHydrochlorothiazide combination; BMI, Body Mass Index; WC, Waist Circumference; SBP, Systolic Blood Pressure; DBP, Diastolic Blood Pressure;

*, Standard Error of Mean; $(\mathrm{N}=30[15 \mathrm{M}+15 \mathrm{~F}]$ per group $)$ 
As shown in Table 1, there was no statistically significant difference observed in the $\mathrm{M}$ vs $\mathrm{F}$ patients in AML, HCZ, and AML-HCZ groups, respectively, with regard to the means of ages, BMIs, as well as the SBP/DBP. Most of the patients had severe (stage 2) hypertension.

The analysis excluded the data for a M patient in the AML group who traveled and so could not report for evaluation at week 48; a F from the AML group who became pregnant and so was withdrawn from the study between wks 36 and 48 as well as a $\mathrm{M}$ patient whose wk 36 result was lost in the AMLHCZ group.

From Table 2, the three drug regimens significantly decreased the BP such that at the end of wk 48, the control rate in groups was $90 \%$ vs $76.7 \%$ for AML, $83.3 \%$ vs $66.7 \%$ for $\mathrm{HCZ}$ and $90 \%$ vs $50 \%$ for AML-HCZ with respect to DBP $<90 \mathrm{mmHg}$ vs $\mathrm{BP}<140 / 90 \mathrm{mmHg}$. The effect of treatment on BMI and HR was statistically insignificant.

Table 3 shows the adverse event profiles during treatment with AML, HCZ and AML-HCZ combination regimens.
During AML monotherapy, there were 39 events (17\%) of which tachycardia, polyuria and weight reduction were the commonest. M vs F distribution was 21 vs 18 (9.2 vs 7.9\%), respectively. During combination therapy when AML was titrated up with HCZ, 22 events $(9.6 \%)$ were recorded and tachycardia and weight reduction were the commonest. $\mathrm{M}$ vs F distribution was 9 vs 13, (3.9 vs 5.7\%), respectively. During HCZ monotherapy, there were 38 events (16.7\%) of which polyuria, lethargy/weakness and weight reduction were commonest. M vs F distribution was 18 vs 20 (7.9 vs $8.8 \%$ ), respectively. When $\mathrm{HCZ}$ was titrated up with AML, there were 55 events (24\%) of which weight reduction, tachycardia, and polyuria were the commonest. $\mathrm{M}$ vs $\mathrm{F}$ distribution was 28 vs 27 (12.3 vs $11.8 \%$ ).

When AML-HCZ was used to initiate combination treatment there were 74 events $(32.5 \%)$ of which weight reduction, tachycardia and lethargy/weakness were the commonest. $\mathrm{M}$ vs $\mathrm{F}$ distribution was 34 vs 40 (14.9 vs $17.5 \%)$.

Table 2. Effects of initiating therapy with $A M L, H C Z$ and $A M L-H C Z$ combination on $B P(m m H g)$ in hypertensive subjects for 48 weeks

\begin{tabular}{|c|c|c|c|c|c|c|c|c|}
\hline \multirow[b]{2}{*}{ Week } & \multirow[b]{2}{*}{ BP } & \multicolumn{3}{|c|}{ Treatment Subgroups (Male) } & \multicolumn{4}{|c|}{ Treatment Subgroups (Female) } \\
\hline & & AML & $\mathrm{HCZ}$ & AML-HCZ & AML & $\mathbf{H C Z}$ & AML-HCZ & Gender Effect \\
\hline \multirow[b]{2}{*}{0} & SBP & $169.67 \pm 2.82$ & $170.33 \pm 2.00$ & $168.00 \pm 4.57$ & $171.67 \pm 3.00$ & $169.00 \pm 1.90$ & $167.67 \pm 4.44$ & \\
\hline & DBP & $103.00 \pm 1.75$ & $104.67 \pm 1.50$ & $106.00 \pm 1.48$ & $105.33 \pm 2.03$ & $104.67 \pm 1.98$ & $107.33 \pm 2.00$ & \\
\hline \multirow{2}{*}{1} & SBP & $160.00 \pm 0.00_{\mathrm{A}}$ & $162.67 \pm 2.00_{\mathrm{A}}$ & $162.00 \pm 3.78_{\mathrm{A}}$ & $160.00 \pm 0.00_{\mathrm{A}}^{\mathrm{b}}$ & $157.34 \pm 2.12^{\mathrm{b}}{ }_{\mathrm{A}}$ & $165.67 \pm 2.28^{\mathrm{a}}$ & \\
\hline & DBP & $107.00 \pm 1.16^{\mathrm{a}}$ & $102.33 \pm 1.88$ & $98.67 \pm 1.92^{\mathrm{b}}{ }_{\mathrm{A}}$ & $102.00 \pm 1.16^{\mathrm{a}}$ & $99.67 \pm 2.01_{\mathrm{A}}^{\mathrm{b}}$ & $100.00 \pm 1.95_{\mathrm{A}}^{\mathrm{b}}$ & \\
\hline \multirow{2}{*}{3} & SBP & $157.00 \pm 3.23_{\mathrm{A}}$ & $156.67 \pm 2.32_{\mathrm{B}}$ & $155.00 \pm 3.09_{\mathrm{B}}$ & $159.00 \pm 3.17_{\mathrm{A}}$ & $152.33 \pm 2.12_{\text {B }}$ & $158.33 \pm 2.66_{\mathrm{A}}$ & \\
\hline & DBP & $90.67 \pm 5.94_{\mathrm{A}}^{\mathrm{b}}$ & $95.67 \pm 1.68^{\mathrm{a}}{ }_{\mathrm{A}}$ & $91.67 \pm 1.16_{\mathrm{B}}$ & $92.67 \pm 1.82_{\mathrm{A}}$ & $95.33 \pm 1.33_{\mathrm{A}}$ & $92.67 \pm 2.48_{\mathrm{B}}$ & \\
\hline \multirow{2}{*}{$6^{\$}$} & SBP & $149.00 \pm 2.85_{\mathrm{B}}$ & $150.33 \pm 2.04_{\mathrm{C}}$ & $148.00 \pm 3.27_{\mathrm{C}}$ & $155.33 \pm 2.95^{\mathrm{a}}{ }_{\mathrm{B}}$ & $147.33 \pm 2.12_{\mathrm{C}}$ & $150.00 \pm 2.39_{\mathrm{B}}$ & \\
\hline & DBP & $87.00 \pm 2.06_{\mathrm{A}}$ & $89.00 \pm 1.48_{\mathrm{B}}$ & $84.33 \pm 1.45_{\mathrm{C}}$ & $87.33 \pm 1.28_{\mathrm{B}}$ & $90.67 \pm 1.88_{\mathrm{B}}$ & $86.00 \pm 2.14_{C}$ & \\
\hline \multirow{2}{*}{$12^{\$}$} & SBP & $145.67 \pm 2.38_{\mathrm{B}}$ & $144.33 \pm 1.75_{D}$ & $142.67 \pm 2.62_{D}$ & $149.33 \pm 3.04^{\mathrm{a}} \mathrm{C}$ & $142.00 \pm 2.00_{\mathrm{D}}^{\mathrm{b}}$ & $143.33 \pm 1.99^{\mathrm{b}} \mathrm{C}$ & $0.198^{\mathrm{NS}}$ \\
\hline & DBP & $79.33 \pm 2.00_{\mathrm{B}}$ & $84.00 \pm 1.63_{\mathrm{C}}$ & $80.00 \pm 1.76_{\mathrm{D}}$ & $83.33 \pm 1.93_{\mathrm{C}}$ & $85.33 \pm 1.33_{\mathrm{C}}$ & $82.67 \pm 1.82_{\mathrm{D}}$ & $0.0002^{* * *}$ \\
\hline \multirow{2}{*}{24} & SBP & $140.67 \pm 1.75_{\mathrm{C}}$ & $138.00 \pm 1.48_{\mathrm{F}}$ & $136.68 \pm 2.05_{\mathrm{E}}$ & $140.67 \pm 2.00_{\mathrm{D}}$ & $139.33 \pm 1.53_{\mathrm{D}}$ & $139.00 \pm 1.63_{\mathrm{D}}$ & \\
\hline & DBP & $76.33 \pm 1.42_{\mathrm{B}}$ & $80.00 \pm 1.38_{\mathrm{D}}$ & $78.67 \pm 1.98_{\mathrm{D}}$ & $80.00 \pm 1.95_{\mathrm{C}}$ & $79.67 \pm 1.42_{\mathrm{D}}$ & $80.33 \pm 1.86_{\mathrm{D}}$ & \\
\hline \multirow{2}{*}{36} & SBP & $134.67 \pm 1.86_{\mathrm{D}}$ & $134.00 \pm 1.22_{\mathrm{F}}$ & $136.00 \pm 1.56_{\mathrm{E}}$ & $135.72 \pm 1.63_{\mathrm{E}}$ & $136.00 \pm 1.22_{\mathrm{D}}$ & $138.00 \pm 1.53_{\mathrm{D}}$ & \\
\hline & DBP & $75.00 \pm 1.29_{\mathrm{B}}$ & $77.33 \pm 1.53_{\mathrm{D}}$ & $76.67 \pm 1.87_{\mathrm{E}}$ & $77.14 \pm 1.94_{\mathrm{D}}$ & $78.67 \pm 1.65_{\mathrm{D}}$ & $78.67 \pm 1.92_{\mathrm{D}}$ & \\
\hline \multirow{2}{*}{48} & SBP & $131.79 \pm 2.07_{\mathrm{D}}$ & $132.67 \pm 1.08_{\mathrm{E}}$ & $135.00 \pm 1.62_{\mathrm{E}}$ & $133.92 \pm 1.30_{\mathrm{E}}$ & $134.67 \pm 1.24_{\mathrm{E}}$ & $136.00 \pm 1.31_{\mathrm{D}}$ & \\
\hline & DBP & $72.14 \pm 1.14_{\mathrm{C}}$ & $76.00 \pm 1.63_{\mathrm{D}}$ & $75.67 \pm 1.61_{\mathrm{E}}$ & $73.57 \pm 1.69_{\mathrm{D}}$ & $77.33 \pm 1.82_{\mathrm{D}}$ & $76.00 \pm 1.90_{\mathrm{D}}$ & \\
\hline
\end{tabular}

Significant differences within columns are indicated by ABCDEF, and within rows by ab $(\mathrm{P}<0.05)$ : Significant treatment effect occurred in weeks $1-12$ and all treatment regimens significantly decreased SBP and DBP; SBP, Systolic Blood Pressure; DBP, Diastolic Blood Pressure; ***, P<0.001; other abbreviations are as used in Table 3.2; $(\mathrm{N}=15$ per subgroup)

Table 3. Adverse events profiles during initiation of therapy with AML, HCZ and AML-HCZ combination in hypertensive subjects for 48 weeks

\begin{tabular}{|c|c|c|c|c|c|c|c|c|c|c|}
\hline \multirow{4}{*}{ Adverse events } & \multicolumn{4}{|c|}{ Amlodipine* } & \multicolumn{4}{|c|}{ Hydrochlorothiazide ${ }^{* *}$} & \multirow{2}{*}{\multicolumn{2}{|c|}{$\begin{array}{l}\text { Amlodipine-Hydrochlorothiazide } \\
\text { (CT } 48 \text { weeks) }\end{array}$}} \\
\hline & \multirow{2}{*}{\multicolumn{2}{|c|}{$\begin{array}{l}\text { MT (12 weeks) } \\
\text { No. of Patients }\end{array}$}} & \multirow{2}{*}{\multicolumn{2}{|c|}{$\begin{array}{l}\text { CT (36 weeks) } \\
\text { No. of Patients }\end{array}$}} & \multirow{2}{*}{\multicolumn{2}{|c|}{$\begin{array}{l}\text { MT(6 weeks) } \\
\text { No. of Patients }\end{array}$}} & \multirow{2}{*}{\multicolumn{2}{|c|}{$\begin{array}{l}\text { CT (42 weeks) } \\
\text { No. of Patients }\end{array}$}} & & \\
\hline & & & & & & & & & No & \\
\hline & $\mathbf{M}$ & $\mathbf{F}$ & $\mathbf{M}$ & $\mathbf{F}$ & $\mathbf{M}$ & $\mathbf{F}$ & $\mathbf{M}$ & $\mathbf{F}$ & $\mathbf{M}$ & $\mathbf{F}$ \\
\hline Polyuria & 5 & 3 & - & - & 6 & 4 & 3 & 3 & 2 & 1 \\
\hline Headache & 2 & 2 & - & - & 1 & 4 & 1 & 2 & - & 2 \\
\hline Postural hypotension & - & - & - & - & - & 1 & - & - & - & 1 \\
\hline Lethargy/weakness & - & - & - & - & 3 & 4 & - & - & 3 & 4 \\
\hline Dizziness & 1 & 3 & - & - & - & - & 1 & 2 & - & - \\
\hline Tachycardia & 6 & 5 & 3 & 5 & 2 & 1 & 9 & 5 & 14 & 13 \\
\hline Peripheral neuropathy/Paraesthesia & - & - & 1 & 2 & - & - & - & 2 & - & 2 \\
\hline Weight reduction & 4 & 3 & 5 & 4 & 4 & 4 & 11 & 11 & 15 & 15 \\
\hline Others & $2+$ & $1 \neq$ & - & - & $1 \mathrm{~s}$ & - & $1 \mathrm{p}$ & - & - & - \\
\hline Total & 21 & 18 & 9 & 13 & 18 & 20 & 28 & 27 & 34 & 40 \\
\hline
\end{tabular}

MT, Monotherapy; CT, Combination Therapy; + , Nausea, Diaphoresis; $\neq$, Dyspepsia; S, Impotence; P, Visual Disturbance $(\mathrm{N}=30$ per group) $* 3$ patients had $>1$ event $* * 5$ patients had $>1$ event 


\section{Discussion}

According to LaPointe and Jollis (18), cardiovascular medications have been cited as one of the most common classes of drugs associated with medication errors and adverse drug reactions which need to be monitored regularly. The Adverse Drug Events Prevention Study Group reported that odds ratio of severe adverse drug events with cardiovascular medications was 2.4 times that of other medications (19). In our study, all the reported adverse events were of mild to moderate intensity, consistent with the known pharmacology of the respective study medications. Patients did not require any active management, hence the rate of adherence was high. In fact, safety is an important factor affecting adherence of patients during long-term treatment, as it is in our study.

The common complaints of weight loss (which patients interpreted as lightness) and tachycardia occurred during the first one to eight weeks. Other complaints of frequent urination, headache, myalgias/cramps, weakness and paresthesia were mild to moderate and did not affect the patients' quality of life. However, tachycardia and weight changes were more marked in the AML-HCZ group than in the other two groups $\mathrm{P}<0.01$. Since treatment in this group started $a b$ initio with the two drugs, the sudden loss in blood volume may provoke compensatory physiological mechanisms leading to increase release of vasoconstrictor effectors such as norepinephrine, angiotensin 2, vasopressin (antidiuretic hormone) or endothelin, that may cause tachycardia and raise BP. The overall manifestation of adverse drug experiences in AML, HCZ and AML-HCZ groups was $26.6 \%, 40.7 \%$, and $32.5 \%$, respectively. Our findings are in agreement with those of Ma et al (8), Oparil et al (20) and Chysant et al (21), who reported that the combination therapy with AML and HCZ demonstrated enhanced antihypertensive effect as well as a good safety and tolerability profile.

Of note and in contrast with the above reports $(8,20-21)$, no patient in this study developed peripheral edema, a common complication of AML treatment (22). This might have been due to the fact that the patients were salt (sodium)sensitive, a phenomenon that leads to abundant natriuresis and diuresis in majority of blacks, the elderly as well as the obese/diabetics $(7,9-10,15-16,23)$. Thus, the combination of AML and HCZ, two agents that specifically address the low-renin, volume-dependent hypertension common in blacks, leads to marked natriuresis and diuresis because of potentiation of effects, and this precludes peripheral edema. Fogari and colleagues (24-25) analysed the ankle-foot volume and pretibial subcutaneous tissue pressure, two objective measures of ankle edema, in hypertensive patients treated with AML. They showed that peripheral edema due to administration of AML could be mitigated by $60-70 \%$ when an angiotensin converting enzyme inhibitor (ACEI) (24) or angiotensin $2 \mathrm{AT}_{1}$ receptor blocker (ARB) (25) was coadministered. In the present study, the combination regimens of AML and HCZ reduced peripheral edema, one of the most common reasons for discontinuing therapy, by $100 \%$, indicating a most favourable outcome in Nigerians.

The occurrence of impotence in one patient in HCZ group during monotherapy is a psychological insult which may have negative implication for drug adherence because of the high premium attached to sex and procreation by Nigerians $(26,27)$.

\section{Conclusion}

This study demonstrates that during antihypertensive treatment with AML and $\mathrm{HCZ}$ in Nigerians, a regimen of AML to which HCZ is subsequently added is associated with the least adverse events profile and provides the best tolerability to patients when compared with a regimen of HCZ to which AML is added as needed or with $a b$ initio AML-HCZ combination therapy. Healthcare providers should take note of this point when treating ethnic Nigerians. In addition, during consultation, they should raise the awareness of the possibility of adverse effects as well as related drug risks to patients and initiate motivational strategies that address these issues. Thus, they can directly challenge intentional (intelligent) non-adherence (by which patients decrease or omit the prescribed dose of a drug in other to minimize side effects), and improve the control of hypertension. However, due to the small number of patients studied, caution should be exercised in interpreting our results or extrapolating our findings to hypertensive black patients in general.

\section{Acknowledgments}

The authors appreciate gratefully the Managements of the hospitals and patients used for this study as well as Neimeth International Pharmaceuticals, Nigeria for donation of amlodipine (Amlovar ${ }^{\mathrm{R}}$ ) tablets and the Nigerian Representative of Novartis Pharma SAS France for donation of hydrochlorothiazide $\left(\right.$ Esidrex $^{\mathrm{R}}$ ) tablets for the study.

\section{References}

[1] R. Lozano, M. Naghavi, K. Foreman, S. Lim, K. Shibuya, V. Aboyans et al. Global and regional mortality from 235 causes of death for 20 age groups in 1990 and 2010: a systematic analysis for the Global Burden of Disease Study 2010. The Lancet, 2012, 380 (9859), 2095-2128

[2] WHO. Preventing chronic disease, a vital investment, 2005, Geneva

[3] P.M. Kearney, M. Whelton, K. Reynolds, P. Muntner, P.K. Whelton, J. He. Global burden of hypertension: analysis of worldwide data. The Lancet, Jan. 2005, 365(9455), 217-223

[4] J. Addo, L. Smeeth, D.A. Leon. Hypertension in sub-Saharan Africa: a systematic review. Hypertension, Dec 2007, 50(6), 1012-1018 
[5] O.O. Akinkugbe. Current epidemiology of hypertension in Nigeria. Archives of Ibadan Medicine, 2003, 1, 3-5

[6] G.B.S. Iyalomhe. Compliance to antihypertensive therapy. Nigerian Clinical Review Journal, 2007, 63, 12-16

[7] G.B.S. Iyalomhe, E.K.I. Omogbai, O.O.B. Iyalomhe. Longterm electrolyte effects during initiation of antihypertensive therapy with amlodipine or hydrochlorothiazide in diabetic Nigerians. American Journal of Medical Sciences and Medicine, 2013, 1(3), 1-7

[8] L. Ma, W. Wang, Y. Zhao, Y. Zhang, Q. Deng, M. Liu, H. Sun, J. Wang, L. Liu. Combination of amlodipine plus angiotensin receptor blocker or diuretics in high-risk hypertensive patients. American Journal of Cardiovascular Drugs, 2012, 12(2), 137142

[9] G.B.S. Iyalomhe, E.K.I. Omogbai, A.O. Isah, O.O.B. Iyalomhe, F.L. Dada, S.I. Iyalomhe. Efficacy of initiating therapy with amlodipine and hydrochlorothiazide or their combination in hypertensive Nigerians. Clinical and Experimental Hypertension. Early online 1-8 2013, DOI: 10.3109/10641963.776570

[10] G.B.S. Iyalomhe, E.K.I. Omogbai, O.O.B. Iyalomhe, S.I. Iyalomhe. Serum and urine electrolyte profiles during amlodipine and hydrochlorothiazide combination therapy in Nigerian patients with essential hypertension. British Journal of Medicine and Medical Research, 2013, 3 (2), 428-441

[11] K.I. Kjellgren, J. Ahlner, B. Dahlof, H. Gill, T. Hedner, R. Saljo. Perceived symptoms amongst hypertensive patients in routine clinical practice- a population-based study. Journal of Internal Medicine, 1998, 244, 325-332

[12] M. Morgan. The significance of ethinicity for health promotion: patients' use of antihypertensive drugs in inner London. International Journal of Epidemiology, 1995, 24(Suppl), 579-584

[13] S. Svenssson, K.I. Kjellgren, J. Ahlner, R. Saljo. Reasons for adherence with antihypertensive medication. International Journal of Cardiology, 2000, 76, 157-163

[14] J. Benson, N Britten. What effects do patients feel from their antihypertensive tablets and how do they react to them? Qualitative analysis of interviews with patients. Family Practice, 2006, 23, 80-87

[15] G.B.S. Iyalomhe, E.K.I. Omogbai, A.O. Isah, S.I. Iyalomhe, O Okhiai, F.L. Dada, O.O.B. Iyalomhe. Comparison of the longterm efficacy and some metabolic effects of initiating therapy with amlodipine or hydrochlorothiazide in hypertensive type 2 diabetic Nigerians. International Journal of Health Sciences and Research, 2014, 4 (7), 149-161

[16] G.B.S. Iyalomhe, E.K.I. Omogbai, R.I. Ozolua. Antihypertensive and biochemical effects of hydrochlorothiazide and furosemide in hypertensive Nigerians. Journal of Medical Sciences, Aug, 2007, 7(6), 977-983
[17] T.G. Pickering, J.E. Hall, L.J. Appel, B.E. Falkner, J. Graves, M.N Hill, D.W. Jones, T. Kurtz, S.G. Sheps, and E.J. Rocella, "Recommendations for blood pressure measurement in humans and experimental animals part1. Blood pressure measurement in humans: a statement for professionals from the Subcommittee of Professional and Public Education of the American Heart Association Council on High Blood Pressure Research", Circulation, 2005, III, 697-716

[18] N.M. LaPointe, J.G. Jollis. Medication errors in hospitalised cardiovascular patients. Archives of Internal Medicine, 2003, $163,1461-1466$

[19] D.C. Classen, S.L. Pestotnik, R.S. Evans, J.P. Burke. Computerised surveillance of adverse drug events in hospital patients, Journal of American Medical Association, 1991, 266, $2847-2850$

[20] S. Oparil, E. Barr, M. Elkins, C. Liss, A. Vrecenaka, J. Edelman. Efficacy, tolerability, and effects on quality of life of losartan, alone or with hydrochlorothiazide, versus amlodipine, alone or with hydrochlorothiazide, in patients with essential hypertension. Clinical Therapeutics, 1996, 18(4), 608-675

[21] S.G. Chrysant, C. Chrysant, J. Trus, A. Hitchcock. Antihypertensive effectiveness of amlodipine in combination with hydrochlorothiazide. American Journal of Hypertension, Jul. 1989, 2(7), 537-541

[22] D. Patel, B. Ganguly. To study the nature of adverse drug reaction of amlodipine in hypertensive patients. International Journal of Pharmaceutical Research, 2010, 2(4), 30-33

[23] E. Orbarzanek, M.A. Proschan, W.M. Vollmer, T.J. Moore. Individual blood pressure responses to changes in salt intake: results from the DASH-Sodium trial. Hypertension, 2003, $42,459-462$

[24] R. Fogari, G.D. Malamani, A. Zoppi. Effect of benazepril addition to amlodipine on ankle edema and subcutaneous tissue pressure in hypertensive patients. Journal of Human Hypertension, 2003, 17(3), 207-212

[25] R. Fogari, A. Zoppi, G. Derosa. Effect of valsartan addition to amlodipine on ankle edema and subcutaneous tissue pressure in hypertensive patients. Journal of Human Hypertension, 2007, 21(3), 220-224

[26] G.B.S. Iyalomhe, S.I. Iyalomhe. Hypertension-related knowledge, attitudes and life-style practices among hypertensive patients in a sub-urban Nigerian community. Journal of Public Health and Epidemiology, 2010, 2(4), 71-77

[27] S. Babaei, M. Moeini, F. Sabouhi, N. Mohammadi. Investigation of experiences of hypertensive patients. Isfahan Journal of Nursing and Midiritery Research, 2008, 13(2), 4346. 